\title{
Professional responsibility and decision-making in the context of a disease-focused model of nursing care: The difficulties experienced by Spanish nurses
}

\author{
Olga Rodrigo \\ School of Nursing, Campus Docent Sant Joan de Déu, University of Barcelona Esplugues de \\ Llobregat, Barcelona, Spain
}

Jordi Caïs

Department of Sociology, University of Barcelona Barcelona, Spain

Cristina Monforte-Royo

Nursing Department, School of Medicine and Health Science. Universitat Internacional de Catalunya, Sant Cugat del Vallés, Barcelona, Spain 


\section{ABSTRACT}

When, in 1977, nurse education in Spain was transferred to universities a more patientcentred, Anglo-American philosophy of care was introduced into a context in which nurses had traditionally prioritised their technical skills. This paper examines the characteristics of the nurse's professional role in Spain, where the model of nursing practice has historically placed them in a position akin to that of physician assistants. The study design was qualitative and used the method of analytic induction. Participants were selected by means of theoretical sampling and then underwent in-depth interviews. The resulting material was analysed using an approach based on the principles of grounded theory. Strategies were applied to ensure the credibility, transferability, dependability and confirmability of the findings. The main conclusion is that nurses in Spain continue to work within a disease-focused model of care, making it difficult for them to take responsibility for decision making.

Keywords: Decision making, grounded theory, nurse-patient relationship, nursephysician relationship, nurse's role, professional role, 


\section{INTRODUCTION}

The origins of modern nursing can be traced back to the work and ideas of Florence Nightingale (1820-1910), whose contributions to nursing practice in the Anglo-American context marked the beginning of a shift in the nurse's role, from doctor's assistant to what we now think of as patient-centred care (Bullough \& Bullough, 1981).

In our country, Spain, the first school of nursing was established in 1896 by Dr Federico Rubio y Galí with the aim of producing "nurses capable of acquiring all that is entailed in the art of tending and caring for others, which is both art and science [...] so as to earn their living in the service of the sick" (Ortega \& Sánchez, 1996, p. 295). The model of nursing that developed as a result was very much focused on the application of technical procedures, such that the role of Spanish nurses was more akin to what in the USA became the responsibility of physician assistants (Domínguez-Alcón, 1986, p. 103; Domínguez-Alcón, Rodriguez \& Miguel, 1983, p. 92; Hernández \& Moral, 1995, p. 103). Indeed, not until 1977, when nurse education was transferred to universities (Boletin Oficial del Estado [Official Gazette of the Spanish government], 1977b), did a more patient-centred philosophy of care, borrowed from the Anglo-American context, begin to be introduced in Spain (Miro-Bonet, 2010).

\section{BACKGROUND}

It is possible to identify two main and - in terms of their associated competences distinct profiles of the professional nurse in Western countries. One profile corresponds to countries such as the USA (Cawley, Cawthon \& Hooker, 2012), Canada (Jones \& StPierre, 2014) and the UK (Drennan et al., 2014), where a distinction is generally made between the role of the professional nurse and that of physician assistants or associates. 
The other profile is more characteristic of countries such as Spain (Domínguez-Alcón, 1986, p. 103), Germany (Kuilman, Sundar \& Cherian, 2013) or Portugal (Mendes \& Mantovani, 2009), where many of the tasks performed by physician assistants or associates in the Anglo-American context are regarded as part of the nurse's role.

According to Larson (1977, p. 40), professions are market-oriented organisations that seek to establish intellectual control over areas of social interest or concern. Through the development of abstract knowledge, professions propose concrete solutions to human problems, thereby ensuring their own survival. Professional autonomy, defined as "the ability of a professional to act in accordance with a system of principles and rules" (Mulero, 2003), has been identified as an important indicator of professionalization within nursing (Tapp, Stansfield \& Stewart, 2005). In this context, autonomy is regarded as a prerequisite for achieving professional status (Ballou, 1998; Holland, 1999) and has been related to job satisfaction among nurses, to a positive working environment and to the quality of care (Finn, 2001; Tonges, Rothstein \& Kikiras, 1998). However, research to date has not explored the extent to which the nursing profession in Spain has incorporated the new philosophy of patient-centred care into the traditional role of physician assistants, and in what ways this has influenced the professional autonomy of Spanish nurses.

\section{METHOD}

\section{Aim}

To describe the characteristics of the nurse's professional role in Spain, where the model of nursing practice has historically placed nurses in a position akin to that of physician assistants. 


\section{Design}

This was a qualitative study using the method of analytic induction, in which the formulation of an initial hypothesis was followed by the selection of extreme cases (Borobia, 2004; Smelter \& Baltes, 2001). The transcripts of interviews with participants were analysed using interpretive description (Thorne, Kirkham \& MacDonald-Emes, 1997; Thorne, Kirkham \& O'Flynn-Magge, 2008).

\section{Sample/Participants}

Participants were selected through a process of theoretical sampling (Smelter \& Baltes, 2001) and according to the following inclusion criterion: having worked as a nurse in Spain for at least ten years since 1982 (the year in which the first wave of nurses graduated with the new Diploma in Nursing) and in at least two of the following areas: patient care, teaching, management, research. This meant that all our participants could be regarded as 'expert nurses' (Benner, 2000). The number of participants to be recruited was established according to the criteria of sufficiency, while seeking the maximum variety of experience and contexts (Seidman, 2013). Sampling continued until theoretical saturation was reached (Strauss \& Corbin, 2002, p. 231).

A total of ten participants were initially interviewed, following which two additional extreme cases (in terms of experience and background) were identified. These cases were chosen in order to explore the possible influence that their specific experience or characteristics might have had on their management of the nursing role. One of these cases was a female nurse manager who had worked in the Anglo-American context; we considered that her greater experience with this model might have led her to adopt a more patient-centred approach. The other extreme case, a male nurse manager, was chosen because the literature suggests that male nurses are more inclined to adopt a technical 
role, and this may have been reflected in his approach to team management. As no new information was gained through these two interviews it was concluded that theoretical saturation had been reached.

The final sample therefore comprised twelve nurses, of whom nine $(75 \%)$ were women. Participants came from a wide range of Spanish regions: Andalusia $(n=2)$, Catalonia ( $n=4)$, Valencia ( $n=2)$, Balearic Islands $(n=1)$, Madrid $(n=1)$, Galicia $(n=1)$ and the Basque Country $(n=1)$. In terms of the contexts in which they had worked, $25 \%$ of them had experience of all four of the aforementioned areas, $33 \%$ had worked in patient care and then as nurse teachers, $33 \%$ had experience of both patient care and management, and $9 \%$ had worked in the areas of nurse management and teaching. Overall, $33 \%$ of participants had obtained a doctorate, a qualification that had given them recognition in the field of research. All the nurses with experience of patient care had worked in both the hospital and primary care settings.

\section{Data collection}

Each of the twelve in-depth interviews lasted between 60 and 90 minutes and followed established guidelines for conducting qualitative interviewing (Seidman, 2013). Table 1 outlines the three topics that were explored sequentially in order to induce the participant's experience (Seidman, 2013, p. 16). All the participants were recruited through contacts that the research team had in university nursing schools across Spain. The initial contact with potential participants was via email and involved providing them with information about the study and requesting their participation. The date and time for a face-to-face interview was then agreed, in a place of the participant's choosing. Interviews were conducted by the lead author, who introduced herself to participants as a nurse teacher. All the interviews were recorded and subsequently transcribed verbatim. 


\section{Ethical considerations}

The study was approved by the Research Ethics Committee. All participants were informed that participation was voluntary, and they all signed informed consent prior to the interviews. The anonymity and confidentiality of all collected data was ensured throughout the study.

\section{Data analysis}

Data were analysed using a grounded theory approach that involved the coding of interview transcripts and application of the constant comparative method (Strauss \& Corbin, 2002, p. 86). The first step involved the open or substantive coding of data, in which fragments of discourse were linked to coding labels. This was followed by focused coding, in which we sought to identify the most significant and/or frequent codes in order to define the emergent categories. Based on the outcome of this focused coding we then drew up provisional categories, specifying their properties and dimensions (axial coding). The application of a coding paradigm throughout the analytic process facilitated the subsequent establishment of relationships between categories and enabled the final theoretical narrative to be produced. In addition, a series of memos were generated in order to provide support for the entire analytic process (Charmaz, 2006, p. 72).

\section{Validity and reliability/Rigour}

In order to ensure the credibility of the analysis, the reported findings are supported by verbatim quotations (see tables 2 and 3) from the interviews with participants. Additionally, an external audit was conducted by an expert in the analysis of qualitative data. Regarding transferability, we clearly described the sampling context and considered the results as working hypotheses that are not susceptible to generalisation. In order to systematise and support the analytic process, work standards were used in conjunction 
with the ATLAS.ti 7.1 software (for operative support) throughout the research process. Finally, data were displayed in the form of conceptual maps and matrices in order to optimise the confirmability of results.

\section{FINDINGS}

Analysis of the twelve interview transcripts led to the identification of three categories that described the professional role and competences of nurses in Spain. These categories were: 'collaborative role alongside the physician in treating disease', 'collaborative role alongside the patient and his/her family in providing care' and 'the difficulty for nurses of assuming the responsibilities that are now associated with their professional role'. Application of the constant comparative method to these categories yielded an overarching core category under which the three initial categories could be subsumed: 'Lack of professional autonomy in a caring role that is disease-focused rather than patientcentred'.

In the following sub-sections we discuss each of the three initial categories and the resulting core category, illustrating them through reference to the verbatim quotations presented in Table 2 (initial categories) and Table 3 (core category). Thus, for example, the label P2:1 in the text indicates that the point being made is supported by quotation P2:1 in the corresponding table.

\section{Collaborative role alongside the physician in treating disease}

A central aspect of the Spanish nurse's role is to work alongside the physician in treating disease. This role, in which nurses are required to acquire and apply a series of technical 
procedures, also reflects how the profession is viewed by the general public in Spain (Arredondo \& Siles, 2009)(P2:1) (P3:2).

MacMillan (2012) points out that professional nursing care has, since the time of Florence Nightingale, evolved on the back of medical specialities. Thus, in order to provide care in hospitals that have become increasingly technological (Bartol, 2015), nurses have had to develop a body of knowledge similar to that required by doctors (MacMillan, 2012). In the Spanish context, the high demands on nurses' time (Parro et al., 2013) is a further factor that has contributed to a greater emphasis being placed on the performance of technical tasks rather than on the tailoring of care to patients' specific needs. With regard to the latter issue, Watson (2006) has identified a similar problem in the North American context (P3:3).

\section{Collaborative role alongside the patient and his/her relatives in providing care}

Another key feature of the Spanish nurse's role is to work together with patients and their relatives in the provision of care $(\boldsymbol{P 1 : 1})$. This kind of collaboration has three characteristics: care must be individualised; the nurse should aim to promote patients' personal autonomy (and that of their relatives) in relation to their health condition; and part of the nurse's professional mission should be to defend the rights of patients within both the health system and the wider social context.

Individualised care implies prioritising the perceived needs of patients (and also of their relatives) while respecting their identity $(\boldsymbol{P 2 : 2 )}$. Thus, patients must be treated as unique human beings (P11:3) who find themselves at a specific stage of the life cycle (P6:4) and whose care needs reflect their particular cultural background (P2:2)(P6:5). The establishment of an adequate nurse/patient — and nurse/relatives — relationship is 
seen as a crucial component of individualised care (P8:6), and this implies that nurses must be capable of empathic communication.

Promoting patients' autonomy can be seen as a form of empowerment (P6:7) that seeks to enable them to take decisions about and responsibility for their own health (P10:8). Interestingly Oliver, Fernandez and Sala (2006) found that in Spain many hospitalised patients did not regard this kind of autonomy as necessary; on the contrary, they preferred to leave decisions over their health to professionals, especially doctors. This may, in part, reflect a lack of awareness among the general public in Spain regarding the right to make their own choices or decisions in relation to their health.

Another key element of the nurse's role in this regard involves supporting and respecting patients' rights. This implies not only an awareness of what it means for an individual to be ill and in a vulnerable state (P11:9) (Watson, 2006), but also, as professionals, to seek to ensure that patients are not exposed to poor or even harmful care practices (P1:10). In this regard, Oliver et al. (2005) noted that many patients described hospitalisation as a depersonalising and stressful experience, as an invasion of personal and private space which at times undermined their sense of dignity. On the plus side, today's generation of patients and relatives tend to be more demanding of their rights and there is now legislation to support this $(P 9: 11)(P 9: 12)(P 1: 13)$.

A final point in relation to the nurse-patient relationship concerns the responsibility which the nursing profession as a whole has when it comes to shaping health policy (P3:14). Nurses need to participate in decision-making processes and develop a degree of political competence that enables them to engage more actively with the health-related aspects of public life (P6:15). In this respect, Brown, Lindell and 
Dolansky (2015) noted that nurses tend to see little value in this kind of political activism, as compared with the importance they ascribe to the caring role.

\section{Difficulty for nurses of assuming the responsibilities that are now associated with their} professional role

Overall, the nursing profession in Spain has struggled to assume the responsibilities that have come to be associated with its professional caring role $(\boldsymbol{P 1 : 1})$. There are several contributing factors here.

One factor has to do with the fact that prior to the transfer of nurse education to universities in 1977 (Boletin Oficial del Estado 1977b), Spanish nurses had not traditionally been involved in decision-making, the latter being seen as the responsibility of physicians (Domínguez-Alcón et al., 1983, p. 92; Domínguez-Alcón 1986, p.103; Hernández \& Moral, 1995, p. 103). Although, in theory, the new Diploma in Nursing was meant, among other things, to raise the status of nursing as a profession, real power still lies with doctors (P3:2). Historically, of course, this has been the case in health care systems across the Western world (Bell, Michalec \& Arenson, 2014; Lancaster, Kolakowsky-Hayner, Kovacich \& Greer-Williams, 2015; MacMillan, 2012; Watson, 2006), and in part it is related to the fact that medicine has successfully legitimised its power by integrating the findings and knowledge of other scientific disciplines (P3:3), thereby underpinning the superiority of its discourse (Pijl-Zieber, 2013).

Interestingly, however, the nursing profession in Spain also appears to have found it difficult to assume the risks associated with its now accepted status. Thus, there remains a tendency among Spanish nurses to leave decision-making and, therefore, responsibility, in the hands of doctors $(P 10: 4)$. 
A second factor to consider has to do with the fact that the nursing profession in Spain continues to be focused on achieving greater visibility within the health care team $(\boldsymbol{P 2 : 5})$, as a way of raising professional status $(\boldsymbol{P 5 : 6})$, rather than on demonstrating the intrinsic value of nursing care in terms of health care outcomes and systems. In this context, it is worth noting a point made by Miró-Bonet (2010), namely that the adoption of Anglo-American conceptual models was one of the strategies used by Spanish nurses in recent decades in an attempt to obtain recognition as an independent profession, distinct from medicine. However, it seems that in Spain these models and theories of nursing have been applied somewhat mechanically, as a way of highlighting the specific contribution that nurses are making to the work of the multidisciplinary team, rather than as a demonstration of the independent professional nurse who is capable of reflective practice (P4:7)(P8:8).

A final factor related to the difficulties experienced by Spanish nurses when it comes to assuming professional responsibilities has to do with the social demands on women, who make up the large majority of the profession. Female nurses are often forced to choose between family responsibilities and their professional development, and they tend to prioritise the former. Schueller-Weidekamm and Kautzky-Willer (2012) noted how female doctors face the same problem, while Bell et al. (2014) point out that women's involvement in the professional workforce continues to be hindered by societal expectations, with men being seen as more competent. A related issue here concerns the continued importance of the extended family in Spanish society, since women's traditional role as primary caregivers (Brullet, 2010; Schueller-Weidekamm \& KautzkyWiller, 2012) impacts on their career possibilities (P4:9) (P4:10). 
Lack of professional autonomy in a caring role that is disease-focused rather than patient-centred

Despite the incorporation of Anglo-American models of nursing into the training that Spanish nurses now receive, their role in practice remains more disease-focused than patient-centred (P1:1)(P6:2). This role has two distinct but related facets. On the one hand, nurses are seen as complementing the work of the physician (Price, Doucet \& Hill, 2014), with the care they provide being seen as integral to the treatment of disease (P2:3). On the other hand, and still with the focus on disease, nurses themselves see their caring role as being performed in collaboration with patients and their relatives $(\boldsymbol{P 1 : 4})$. It is here, in the relationship with the patient and his or family, that nurses can escape to some extent the supervision and authority of physicians and begin to construct their professional autonomy as providers of true nursing care (Weiland, 2015).

When, in 1977, nurse education in Spain was transferred to universities (Boletin Oficial del Estado 1977a) this brought legal recognition of a new role for nurses, namely, as independent members of the healthcare team whose specific task was to provide what was termed "professional nursing care" (Santo-Tomás, 2000, p. 105). According to Holden (1991), this kind of autonomous practice, in which the professional has the power to make decisions concerning the wellbeing of others, implies not only personal and professional responsibility but also accountability. In Spain, it appears that the nursing profession has found it difficult to assume the responsibilities associated with this role $(P 1: 5)(P 4: 6)$. Thus, although Spanish nurses are supposed, in theory, to have acquired greater decision-making capacity through their university-based training, this is often not reflected in practice $(\boldsymbol{P 8 : 7 )}$.

\section{DISCUSSION}


The results of this study suggest that nurses in Spain continue to work within a diseasefocused model of care. Their role is fulfilled through the relationships they establish with both physicians — with whom a care plan must be defined — and patients, with whom an agreement must be reached regarding the treatment to be followed. However, Spanish nurses seem to find it difficult to assume responsibility for decision making, suggesting that they still lack a degree of professional autonomy.

\section{Professional role of disease-focused care}

The role performed by nurses in Spain prioritises many of the skills associated with physician assistants or associates in the Anglo-American context (Bartol, 2015; Cawley, et al., 2012; Drennan et al., 2014). The disease focus of their practice means that Spanish nurses are expected to acquire high levels of technical and practical skills, this despite the fact that their university training is now based more on a patient-centred model of care (Bartol, 2015). Although the nursing profession in Spain has sought explicitly to reject the assignment of medically-oriented tasks (Cawley et al., 2012), the high demands on nurses' time in the hospital setting (Warelow, Edward \& Vinek, 2008; Parro et al. 2013) has favoured the continuation of a more disease-focused practice, with a holistic and individualised approach to care remaining more as a theoretical background (Watson, 2006; Weiland, 2015).

There are at least two factors that may account for why Spanish nurses, within an overall disease-focused model of care that emphasises technical and instrumental procedures (Celma \& Acuña, 2009), have combined the traditional role of physician assistant with the patient-centred model of care they are taught during their university training. The first concerns the nature of the health system in Spain, which, since the corresponding legislation was passed in 1963 (Boletín Oficial del Estado, 1963), has 
primarily operated according to a model of medical care (Miró-Bonet, Gastaldo \& Gallego-Caminero, 2008). The other factor has to do with the fact that Spanish nurses developed their technical skills in response to the needs of the health system; it has been argued that the resulting social prestige led to consolidation of the profession (SantoTomás, 2000, p. 101; Sellán, 2010, p. 235) and paved the way for the subsequent transfer of nurse education to universities (Siles, 2011, p. 451). Together, these factors may have led Spanish nurses to focus more on the illness (in line with the traditional role of physician assistants) than on the patient. The question that remains is to what extent Spanish nurses regard this disease-focused model of care as a specific kind of nursing practice.

These same factors are, of course, present in the Anglo-American context in which the patient-centred model of care originated (Bullough \& Bullough, 1981). Indeed, some authors have suggested that nurses in many countries continue to be seen primarily as assistants to the medical profession (Pender \& Spilsbury, 2014). In the specific case of the USA, an additional factor is that the health system prioritises medical procedures and care (Watson, 2006). An interesting line of research would therefore be to investigate whether nurses in the Anglo-American context also resort to a disease-focused model in practice, despite the overarching philosophy of patient-centred care. This would shed light on the extent to which nursing practice in Western societies actually fulfils the expressed goals of the patient-centred model.

The nurse-physician and nurse-patient relationships as the primary means through which a disease-focused role is fulfilled

The professional role ascribed to Spanish nurses, namely the provision of diseasefocused care, appears to have two inter-related dimensions. On the one hand, the nurse's 
approach to care implies the application of techniques and treatments whose aim is to cure disease. At the same time, however, Spanish nurses have the task of ensuring that these techniques and treatments are properly applied to - and can be followed by - a given individual, and thus the focus switches to the patient. In the former case, the emphasis is on the relationship between physician and nurse, whereas in the latter it is the nurse-patient relationship that comes to the fore, and it is here that nurses see their true role (Weiland, 2015).

When it comes to understanding the nurse-physician relationship in Spain, it is helpful to consider what Stein (1967) referred to as the "doctor-nurse game", that is, a relationship in which medical power is maintained at nurses' expense, especially in the sense of minimising the intellectual contribution that nursing can make to society. As the goal of this "game" is to maintain the existing social status of the two disciplines, any kind of genuine collaboration is difficult to establish. In this context, Pilj-Zieber (2013) points out that the functioning of health care systems continues to be influenced by the widely held view that nurses ultimately should follow medical orders. For their part, Brown et al. (2015) argue that, despite the unique and specific contribution that nurses make to health care systems, the fact that doctors fail to recognise the value of information derived from nursing care means that the two professions tend to operate in parallel rather than as partners in collaboration. Lancaster et al. (2015) suggest that this lack of collaboration can have serious repercussions, including medical errors, which are a major cause of mortality in the USA.

Despite the continued disease focus of nursing in Spain, nurses see the relationship with the patient as being the key to their practice. The pivotal role played by this interaction has, of course, been highlighted in numerous studies (see, for example, Sieger, Fritz \& Them, 2011). It is also reflected in Joyce Travelbee's human-to-human 
relationship model, in which nursing is defined as the process through which the nurse seeks to help the patient cope with illness or suffering, and if necessary to find meaning in these experiences (Alligood \& Marriner-Tomey, 2010, p. 61). For Travelbee, qualities such as empathy, compassion and sympathy are central to the caring role (Alligood \& Marriner-Tomey, 2010, p. 61), especially in the organisational context of health institutions, where a compassionate attitude may otherwise be lacking (Moses, 1994). This view of the caring role, consistent with the Christian values of vocation, altruism and charity, is reflected in the traditional approach to nursing in Spain (Hernández, 2006; Miró-Bonet, Gastaldo \& Gallinero-Caminero, 2008), as well as in that of other Western societies (Carter, 2014).

However, when, in 1977, nurse education in Spain was transferred to universities, the new generation of nurses were required to adopt a more scientific perspective on care (García \& Martínez, 2001), one based on theories and models of nursing that were borrowed from the Anglo-American context (Miró-Bonet, 2010; Rodrigo, Caïs \& Monforte-Royo, 2016). What is unclear, however, is the extent to which the specific models and theories that were chosen were consistent with the existing epistemological tradition in the Spanish context, one based on the nurse-patient relationship. In fact, various studies conducted both in Spain (Arreciado \& Isla, 2015; López-Parra, SantosRuiz, Varez-Peláez, Abril-Sabater, Rocabert-Luque, Ruiz-Muñoz \& Mañe-Buxó, 2006; Rodrigo, Caïs \& Monforte-Royo, 2017) and in other countries (Holt, Barrett, Clarke \& Monks, 2000; Warelow et al., 2008; Watson, 2006) have highlighted the gap between the theories and models of nursing that are taught in universities and the actual clinical practice of nurses. Consequently, it might be interesting to examine the applicability of theories such as the 'theory of moral consciousness and communicative action' (Sumner, 2001, 2006) that are more consistent with the 'disease-focused model' under which 
Spanish nurses work. This theory, which as a middle-range theory has proven to be useful for demonstrating the evidence base of nursing practice (Sumner \& Fisher, 2008), considers care to be a two-way communicative action between nurse and patient, the usual goal of which is to treat illness (Sumner, 2006). In the context of this relationship, the task for the nurse, in terms of reflection, is to reach an understanding of the illness, the body's response and the treatment required. As for the patient, he or she must acknowledge the need for nursing care so as to relinquish control over his or her health/illness (Sumner, 2010).

\section{Lack of professional autonomy in a caring role that is disease-focused}

The nursing profession in Spain appears to suffer from a lack of power, and nurses seem to experience limited professional autonomy in a context defined by a disease-focused model of care. This is illustrated by their difficulties at the level of decision-making and in assuming the responsibilities that are now, in theory, an established part of their role.

One factor contributing to this situation concerns the power relationships that operate within the Spanish health care system, such that the greatest decision-making capacity is assigned to the medical profession. The imbalance of power that nurses perceive has been widely reported across many Western nations (Bell et al., 2014; Lancaster et al., 2015; MacMillan, 2012; Watson, 2006), as well as in Asian countries such as China and Japan (Tang et al., 2013), and it is regarded as a source of hostile relationships between doctors and nurses. Furthermore, it not only serves to render invisible the specific contribution made by nurses (Weiland, 2015) but also fosters in them a lack of professional autonomy, dissatisfaction and, in some cases, withdrawal from the nursing profession (Tang et al., 2013). 
There is, however, evidence of a progressive shift towards a more collaborative relationship between doctors and nurses (Lancaster et al., 2015; Tang et al., 2013), and this could help to boost nurses' confidence in their decision-making abilities. In this regard, Tang et al. (2013) suggest that collaboration could be improved through the use of strategies such as inter-professional education to improve mutual awareness, or interdisciplinary ward rounds based on the model of the 'conductorless orchestra', whereby the patient is the focus and each discipline offers its specific perspective (Khodyakov, 2007; Lancaster et al., 2015). A similar point was made by McLain (1988) who argued that greater respect and collegiality between the two professions might result were nurses better able to integrate their professional role alongside that of physicians.

A second factor underpinning nurses' lack of power derives from the fact that the profession has traditionally been a female-dominated one. In both the world of business and in health care systems, women encounter a series of hidden barriers that limit their decision-making capacity to that associated with the level of middle management, the socalled glass ceiling (Carnes, Morrissey \& Geller, 2008; Crawford, 1993; SchuellerWeidekamm \& Kautzky-Willer, 2012). In addition, the role into which women are socialised encourages them to put family commitments ahead of their own professional development (Bell et al., 2014; Brullet 2010; Schueller-Weidekamm \& Kautzky-Willer, 2012).

\section{LIMITATIONS}

A primary limitation of our analysis concerns the absence of previous studies that have specifically examined the professional role of nurses in the Spanish context. In order to 
given meaning to and enable comparison of our findings we have therefore made reference to research conducted in other contexts. A further limitation of our study is that two members of the research team are both nurses and women, a fact that may have introduced a degree of bias into both the interpretation of qualitative data and the literature review on which the theoretical narrative is based. In an attempt to minimise this bias the whole research process was subjected to external audit.

\section{CONCLUSION}

The role of nurses in Spain remains rooted in a disease-focused model of care, this being the result of a socio-historical context of professional socialisation that has emphasised the acquisition and application of practical and technical skills, similar to those performed by physician assistants or associates in the Anglo-American context. This role is enacted through two distinct but inter-related relationships: the doctor-nurse relationship, the aim of which is to draw up a disease-oriented care plan, and the nurse-patient relationship, where the goal is to ensure that the agreed treatment is properly applied to - and followed by - the patient. However, it is the establishment of a relationship with the patient that Spanish nurses regard as their specific contribution, and it is here that they see the possibility of performing what they consider to be their true role.

It can be concluded that the nursing profession in Spain, and in Western societies in general, still finds it difficult to engage in decision-making to assume responsibilities that are now, in theory, considered part of the nurse's professional role. One of the factors contributing to this situation is the power that has traditionally been exercised by the medical profession, which tends to overlook the specific contribution that nurses make. A second and related factor concerns the power relationships to which a predominantly female nursing profession is subject in a world that is still male dominated, one in which 
women continue to experience social pressure to prioritise family responsibilities over a professional career. 


\section{REFERENCES}

Alligood, M.R., \& Marriner-Tomey, A. (2010). Modelos y teorías en enfermería [Models and theories in nursing]. Séptima ed., Barcelona: Elsevier Mosby.

Arreciado, A., \& Isla, M. (2015). Theory and practice in the construction of professional identity in nursing students: A qualitative study. Nurse Education Today, 35(7), 859-863. doi:10.1016/j.nedt.2015.03.014

Arredondo, C.P., \& Siles J. (2009). Tecnología y Humanización de los Cuidados: Una mirada desde la teoría de las relaciones interpersonales [Technology and the humanisation of care: A view based on the theory of interpersonal relations]. Index de Enfermeria, 18(1), 1-7.

Ballou, K. (1998). A concept analysis of autonomy. Journal of Professional Nursing, 14(2), 102-110. doi: 10.1016/S8755-7223(98)80038-0

Bartol, T. (2015). Nurse practitioners: Enhancing healthcare for 50 years. Nurse Practitioner, 40 (6), 14-6. doi:10.1097/01.NPR.0000465128.80771.ec

Bell, A.V., Michalec, B., \& Arenson C. (2014). The (stalled) progress of interprofessional collaboration: The role of gender. Journal of Interprofessional Care, 28(2), 98-102. doi: 10.3109/13561820.2013.851073

Benner, P. (2000). The wisdom of our practice. American Journal of Nursing, 100(10), 99-105.

Boletín Oficial del Estado [Official Gazette of the Spanish Government] (1963). Ley 193 sobre Bases de la Seguridad Social del 28 de diciembre de 1963 [Law 193 on the Basis of Social Security, 28 December 1963] 18181-18190. 
Boletin Oficial del Estado [Official Gazette of the Spanish Government] (1977a). Orden del 1 de abril de 1977 [Order of 1 April 1977], 4008-4011.

Boletin Oficial del Estado [Official Gazette of the Spanish Government] (1977b). Real Decreto [Royal Decree] 2128/1977.

Borobia, R. (2004). La Hipótesis en estudios cualitativos: El caso de la inducción analítica en una investigación sobre adolescencia [The hypothesis in qualitative research: The use of analytical induction in a study of adolescence]. Revista Pilquen, Sección Ciencias Sociales, V(6), 1-12.

Brown, S.S., Lindell, D.F., Dolansky, M.A., \& Garber, J.S. (2015). Nurses' professional values and attitudes toward collaboration with physicians. Nursing Ethics, 22(2), 205-216. doi: 10.1177/0969733014533233

Brullet, C. (2010). Cambios familiares y nuevas políticas sociales en España y Cataluña: El cuidado de la vida cotidiana a lo largo del ciclo de vida [Changes in the family and new social policies in Spain and Catalonia: Everyday care across the life cycle]. Educar, 45, 51-79.

Bullough, B. \& Bullough,V. (1981). Educational problems in a woman's profession. Journal of Nursing Education, 20 (7), 6-17. doi: 10.3928/0148-4834-19810901-03

Carnes, M., Morrissey, C. \& Geller, S.E. (2008). Women's health and women's leadership in academic medicine: Hitting the same glass ceiling?. Journal of Women's Health, 17(9), 1453-1462. doi: 10.1089/jwh.2007.0688

Carter, M. (2016). Vocation and altruism in nursing: The habits of practice. Nursing Ethics, 21 (6), 695-706. 
Cawley, J., Cawthon, E., \& Hooker, R. (2012). Origins of the physician assistant movement in the United States. Journal of the American Academy of Physician Assistants, 25(December), 36-41. doi: 10.1177/0969733013516159

Celma, M., \& Acuña, A. (2009). Influencia de la feminización de la enfermería en su desarrollo profesional [Nursing as a predominantly female profession: The consequences for professional development]. Revista de Antropología Experimental, 9(9), 119-136.

Charmaz, K. (2006). Constructing grounded theory: A practical guide through qualitative analysis. London: Sage.

Crawford, D. (1993). The glass ceiling in nursing management. Nursing Economics, 11(6), 335-341.

Domínguez-Alcón, C. (1986). Los cuidados y la profesión enfermera en España [Care and the nursing profession in Spain]. Madrid: Ediciones Pirámide.

Domínguez-Alcón, C., Rodriguez, J.A.\& Miguel, J. (1983). Sociología y enfermería [Sociology and nursing]. Madrid: Ediciones Pirámide.

Drennan, V.M., Halter, M., Brearley, S., Carneiro, W., Gabe, J.; Gage, H., Grant, R., Joly, L., \& de Lusignan, S. (2014). Investigating the contribution of physician assistants to primary care in England: A mixed-methods study. Health Services and Delivery Research, 2(16). doi: 10.3310/hsdr02160

Finn, C. (2001). Autonomy: An important component for nurses' job satisfaction. International Journal of Nursing Studies, 38(3), 349-357. doi: 10.1016/S00207489(00)00065-1 
García, C., \& Martínez, M.L (2001). Historia de la enfermería: Evolución histórica del cuidado enfermero [History of nursing: The historical development of nursing care]. Madrid: Elsevier.

Hernández, F. (2006). Las Hijas de la Caridad en la profesionalización de la enfermería [The role of the Daughters of Charity in the professionalisation of nursing]. Cultura de los cuidados, 10(20), 39-49. doi: 10.5565/rev/papers/v98n1.342

Hernández, J. \& Moral, P. (1995). Historia de la enfermería:Un análisis histórico de los cuidados de enfermería [History of nursing: A historical analysis of nursing care]. Madrid: McGraw-Hill/Interamericana de España.

Holden, R.J. (1991). Responsibility and autonomous nursing practice. Journal of Advanced Nursing, 16(4), 398-403. doi: 10.1111/j.1365-2648.1991.tb03428.x

Holland, G. (1999). Professional nurse autonomy: Concept analysis and application to nursing education. Journal of Advanced Nursing, 30(2), 310-318.

Holt, J., Barrett, C., Clarke, D.\& Monks, R. (2000). The globalization of nursing knowledge. Nurse Education Today, 20(6), 426-431. doi: 10.1353/bhm.1998.0106

Jones, I.W., \& St-Pierre, N.(2014). Physician assistants in Canada. JAAPA: Official Journal of the American Academy of Physician Assistants, 27(3), 11-13. doi: 10.1097/01.JAA.0000443808.97164.cb

Khodyakov, D. (2007). The complexity of trust-control relationships in creative organizations: Insights from a qualitative analysis of a conductorless orchestra. Social Forces, 86(1), 1-22. doi: 10.1353/sof.2007.0100 
Kuilman, L., Sundar, G. \& Cherian, K. (2013). Physician assistant education in Germany. The Journal of Physician Assistant Education, 23(2), 56-60.

Lancaster, G., Kolakowsky-Hayner, S., Kovacich, J. \& Greer-Williams N. (2015). Interdisciplinary communication and collaboration among physicians, nurses, and unlicensed assistive personnel. Journal of Nursing Scholarship, 47(3), 275-84. doi: 10.1111/jnu.12130

Larson, M. (1977). The rise of professionalism: A sociological analysis, Berkeley and Los Angeles: University of California Press.

López-Parra, M., Santos-Ruiz, S., Varez-Pelaez, S., Abril-Sabater, D., Rocabert-Luque, M., Ruiz-Muñoz, M. \& Mañe-Buxó, N. (2006). Reflexiones acerca del uso y utilidad de los modelos y teorías de enfermería en la práctica asistencial [Reflections on the use and utility of nursing models and theories in clinical practice]. Enfermería Clínica, 16(4), .218-221. doi: 10.1016/S1130-8621(06)71217-7

MacMillan, K.M. (2012). The challenge of achieving interprofessional collaboration: Should we blame Nightingale? Journal of Interprofessional Care, 26(5), 410-5. doi: $10.3109 / 13561820.2012 .699480$

McLain, B.R. (1988). Collaborative practice: The nurse practitioner's role in its success or faiture. Nurse Practitioner, 13(8), 31-36.

Mendes, F.R.P., \& Mantovani, M.D.F. (2009). Ensino de enfermagem em Portugal: Contributos para a sua história [Nurse education in Portugal: Contributions to its history]. Cogitare Enfermagem, 14(2), 2-7. doi: 10.5380/ce.v14i2.15632 
Miró-Bonet, M. (2010). Los modelos conceptuales, una estrategia de poder con implicaciones profesionales [Conceptual models, a strategy of power with professional implications]. Enfermeria Clinica, 20(6), 360-365. doi: 10.1016/j.enfcli.2010.09.002

Miró-Bonet, M., Gastaldo, D., \& Gallego-Caminero, G. (2008). ¿Por qué somos como somos? Discursos y relaciones de poder en la constitución de la identidad profesional de las enfermeras en España (1956-1976) [Why are we as we are? Discourse and power relations in the construction of professional identity among Spanish nurses (1956-1976)]. Enfermeria Clinica, 18(1), 26-34. doi: 10.1016/S11308621(08)70690-9.

Moses, M. (1994). Caring incidents: A gift to the present. Journal of Holistic Nursing, 12(2), 193-203.

Mulero, A. (2003). Autonomía profesional en la práctica de terapia física [Professional autonomy in the practice of physical therapy]. Revista Iberoamericana de Fisioterapia y Kinesiología, 6, 91-100.

Oliver, J., Fernandez, J., \& Sala, J. (2006). Pacientes, médicos y enfermeros: Tres puntos de vista distintos [Patients, doctors and nurses: Three different points of view]. Medicina Preventiva, 20(6), 465-472. doi: 10.1157/13096522.

Ortega, G., \& Sanchez, N. (1996). Historia de la enfermeria en España (desde la antigüedad hasta nuestros días) [History of nursing in Spain (from antiquity to the present day)]. In Historia de la Enfermería en España: Desde la antigüedad hasta nuestros dias (pp. 287-323) [History of nursing in Spain: From antiquity to the present day]. Madrid : Síntesis. 
Parro, A., Serrano, P., Ferrer, C., Serrano, M., de la Puerta, M.L., Barberá, A., Morales, J.M., \& Gomez, P.(2013). Influence of socio-demographic, labour and professional factors on nursing perception concerning practice environment in primary health care. Atencion Primaria, 45(9), 476-485. doi: 10.1016/j.aprim.2012.12.015.

Pender, S., \& Spilsbury, K. (2014). The nursing profession: Public image, self-concept and professional identity. A discussion paper. Journal of Advanced Nursing, 70(2), 295-309. doi: 10.1111/jan.12177

Pijl-Zieber, E. (2013). Doctors' orders and the language of representation. Nursing Philosophy, 14(2), 139-47. doi:10.1111/nup.12001.

Price, S., Doucet, S., \& Hall, L.M. (2014). The historical social positioning of nursing and medicine: Implications for career choice, early socialization and interprofessional collaboration. Journal of Interprofessional Care, 28(2), 103-9. doi: 10.3109/13561820.2013.867839.

Rodrigo, O., Caís, J., \& Monforte-Royo, C. (2016). The influence of Anglo-American theoretical models on the evolution of the nursing discipline in Spain. Nursing Inquiry (Accepted 19.11.16). doi: 10.1111/nin.12175

Santo-Tomás, M. (2000). Historia de la Enfermería [History of nursing]. In C. Fernández Ferrín, ed. Enfermería Fundamental (pp. 3-129) [Fundamentals of nursing]. Masson: Barcelona.

Schueller-Weidekamm, C., \& Kautzky-Willer, A. (2012). Challenges of work-life balance for women physicians/mothers working in leadership positions. Gender Medicine, 9(4), 244-450. doi: 10.1016/j.genm.2012.04.002. 
Seidman, I. (2013). Interviewing as qualitative research: A guide for researchers in education and the social sciences. New York: Teachers College Press.

Sellán, M.C. (2010). La Profesión va por dentro: Elementos para una historia de la enfermeria española contemporánea [Inside the profession: Elements for a history of contemporary nursing in Spain]. 2nd ed., Madrid: FUDEN.

Sieger, M., Fritz, E., \& Them, C. (2011). In discourse: Bourdieu's theory of practice and habitus in the context of a communication-oriented nursing interaction model. Journal of Advanced Nursing, 68(2), 480-489. doi: 10.1111/j.13652648.2011.05783.x.

Siles, J. (2011). Historia de la enfermería [History of nursing]. Madrid: Difusión Avances de Enfermería.

Smelter, N., \& Baltes, P.B. (2001). Analytic Induction. Encyclopedia of the Behavioral Sciences.

Stein, L.I. (1967). The doctor-nurse game. Archives of General Psychiatry, 16, 699-703.

Strauss, A., \& Corbin, J. (2002). Bases de la investigación cualitativa: Técnicas y procedimientos para desarrollar la teoría fundamentada [Basics of qualitative research: Techniques and procedures for developing grounded theory]. Medellín: Universidad de Antioquía.

Sumner, J. (2001). Caring in nursing: A different interpretation. Journal of Advanced Nursing, 35(6), 926-932. doi: 10.1046/j.1365-2648.2001.01930.x 
Sumner, J. (2006). Concept analysis: The moral construct of caring in nursing as communicative action. International Journal for Human Caring, 10(1), 8-16.

Sumner, J. (2010). Reflection and moral maturity in a nurse's caring practice: A critical perspective. Nursing Philosophy, 11, 159-169. doi: 10.1111/j.1466769X.2010.00445.X

Sumner, J.F., \& Fisher, W.P. (2008). The moral construct of caring in nursing as communicative action: The theory and practice of a caring science. Advances in Nursing Science, 31(4), 19-36. doi: 10.1097/01.ANS.0000341418.88715.c9.

Tang, C.J., Chan, S.W., Zhou, W.T., \& Liaw, S.Y. (2013). Collaboration between hospital physicians and nurses: An integrated literature review. International Nursing Review, 60(3), 291-302. doi: 10.1111/inr.12034.

Tapp, D., Stansfield, K., \& Stewart, J. (2005). La autonomía en la práctica de enfermeria [Autonomy in nursing practice]. Revista Aquichan, 5(5), 114-127.

Thorne, S., Kirkham, R., \& MacDonald-Emes, J. (1997). Focus on qualitative methods. Interpretive description: A noncategorical qualitative alternative for developing nursing knowledge. Research in Nursing \& Health, 20, 169-177. doi: 10.1002/(SICI)1098-240x.

Thorne, S., Kirkham, R., \& O'Flynn-Magge, K. (2008). The analytic challenge in interpretive description. International Journal of Qualitative Methods, 3, 1-11. doi: $10.1177 / 160940690400300101$. 
Tonges, M., Rothstein, H., \& Kikiras, H. (1998). Sources of satisfaction in hospital nursing practice: A guide to effective job design. The Journal of Nursing Administration, 28(5), 47-61. doi: 10.1097/00005110-199805000-00008

Warelow, P., Edward, K.L., \& Vinek, J. (2008). Care: What nurses say and what nurses do. Holistic Nursing Practice, 22(3), 146-153. doi:

10.1097/01.HNP.0000318023.53151.33.

Watson, J. (2006). Caring theory as an ethical guide to administrative and clinical practices. JONA'S Healthcare Law, Ethics and Regulation, 8(3), 87-93. doi:10.1097/00128488-200607000-00008.

Weiland, S. (2015). Understanding nurse practitioner autonomy. Journal of the American Association of Nurse Practitioners, 27, 95-104. doi: 10.1002/23276924.12120. 